\title{
Heparan Sulfate Glycosaminoglycan Mimetic M402
}

National Cancer Institute

\section{Source}

National Cancer Institute. Heparan Sulfate Glycosaminoglycan Mimetic M402. NCI

Thesaurus. Code C102749.

\begin{abstract}
A low molecular weight heparin derivative and heparan sulfate proteoglycan (HSPG) mimetic with no or minimal anticoagulant activity and potential antineoplastic activities. Upon administration, M402 mimics HSPGs by binding to and inhibiting various heparinbinding growth factors, chemokines, and cytokines such as VEGF, HGF, FGF2, SDF-1a, heparanase and P-selectin all of which are essential for tumor ang iogenesis and metastasis to occur. This inhibits heparin binding growth factor-mediated signaling and disrupts tumor-stromal interactions eventually leading to an inhibition of angiogenesis and tumor cell progression. In addition, M402 may enhance the cytotoxic effect of other chemotherapeutic agents.
\end{abstract}

